\title{
GAMBARAN PELAKSANAAN TIMBANG TERIMA OLEH PERAWAT DI RUANG RAWAT INAP RSUD JARAGA SASAMEH BUNTOK
}

\author{
Septi Machelia Champaca Nursery ${ }^{1}$, Lucia Andi Chrismilasari ${ }^{2}$, Taria ${ }^{3}$
}

\author{
1.2 Dosen STIKES Suaka Insan Banjarmasin, 3. Mahasiswa STIKES Suaka Insan Banjarmasin \\ Jln. Zafri Zam-Zam No.8, Kalimantan Selatan, Email : septi01nursery@gmail.com
}

\begin{abstract}
Abstrak
Pendahuluan : Timbang terima merupakan suatu cara dalam menyampaikan sesuatu (laporan) yang berkaitan dengan keadaan klien, waktu dimana terjadi perpindahan atau transfer tanggungjawab tentang pasien dari perawat yang satu ke perawat yang lain.Hasil studi pendahuluan menunjukkan dari 10 perawat yang diwawancara adalah 8 perawat tidak melaksanaan bedside handover dan timbang terima sesuai dengan SOP dengan alasan lupa dengan SOP timbang terima, tidak pernah membaca SOP, sedangkan 2 perawat telah melaksanakan timbang terima sesuai dengan SOP yang telah ditentukan. Hal tersebut dapat berdampak terjadinya penurunan kualitas pelayanan keperawatan rumah sakit seperti resiko terjadinya kejadian tidak diharapkan (KTD). Adapun tujuan dari penelitian ini adalah mengetahui gambaran pelaksanaan timbang terima oleh perawat di ruang rawat inap RSUD Jaraga Sasameh. Metode: Jenis penelitian yang digunakan dalam penelitian ini adalah penelitian kuantitatif dengan menggunakan rancangan penelitian deskriptif dan teknik observasi dalam pengumpulan data. Sampel dalam penelitian ini berjumlah 50 orang perawat pelaksana. Jumlah sampel diambil dengan tehnik simple random sampling dan cluster sampling. Analisis data melalui analisa univariat dengan menggunakan tabel distribusi frekuensi. Hasil: Hasil observasi I dan II yaitu berkategori cukup sebanyak 44 responden (88\%) dan baik 6 responden (12\%) dan Observasi III yang berkategori kurang 2 (4\%), cukup 43 (86\%), dan baik 5 (10\%). Observasi dilakukan sebanyak 3 kali untuk satu responden dengan rata-rata waktu yang diperlukan satu kali observasi adalah 5 sampai 7 menit. Kesimpulan: Sebagian besar perawat RSUD Jaraga Sasameh telah melakukan proses timbang terima dengan cukup baik. Hasil observasi I, II, dan III menunjukkan bahwa timbang terima dilakukan dengan cukup baik sebanyak lebih dari $80 \%$. Rekomendasi : Perawat dapat meningkatkan pengetahuan dan jenjang pendidikan dari DIII Keperawatan ke jenjang pendidikan yang lebih tinggi yaitu Ners, agar lebih memahami dan dapat mengaplikasikan ilmu yang didapat khususnya aplikasi proses timbang terima asuhan keperawatan di ruang rawat inap.
\end{abstract}

Kata Kunci: Perawat Pelaksana, Pelaksanaan Timbang Terima.

\begin{abstract}
Introduction: Weighing in is a way of conveying something (report) related to the client's condition, the time when there is a transfer or transfer of responsibility about the patient from one nurse to another. Carried out bedside handovers and weigh-ins in accordance with the SOP on the grounds that they forgot the SOP for the weigh-in, never read the SOP, while 2 nurses had carried out the weigh-in in accordance with the predetermined SOP. This can result in a decrease in the quality of hospital nursing services such as the risk of unexpected events (KTD). The purpose of this study was to find out the description of the implementation of weighing and receiving by nurses in the inpatient room at the Jaraga Sasameh Hospital. Methods: The type of research used in this research is quantitative research using descriptive research design and observation techniques in data collection. The sample in this study amounted to 50 implementing nurses. The number of samples was taken by using simple random sampling and cluster sampling techniques. Data analysis through univariate analysis using a frequency distribution table. Results: The results of observations I and II are in the sufficient category as many as 44 respondents (88\%) and both 6 respondents (12\%) and Observation III which are categorized as less 2 (4\%), enough 43 (86\%), and good 5 (10\%). Observations were made 3 times for one respondent with the average time required for one observation is 5 to 7 minutes. Conclusion: Most of the nurses at the Jaraga Sasameh Hospital have carried out the weighing process quite well. The results of observations I, II, and III showed that the weighin was carried out quite well by more than 80\%. Recommendation: Nurses can increase their knowledge and education level from DIII Nursing to a higher education level, namely Nurses, in order to better understand and be able to apply the knowledge gained, especially the application of the process of weighing and receiving nursing care in inpatient rooms.
\end{abstract}

Keywords: Implementing Nurse, Implementation of Weighing Accept. 


\section{PENDAHULUAN}

Rumah sakit merupakan sarana penyedia layanan kesehatan yang professional dan bertanggung jawab untuk masyarakat sekaligus sebagai instansi penyedia jasa pelayanan kesehatan perorangan secara paripurna dan memiliki peran yang sangat strategis untuk mewujudkan derajat kesehatan yang setinggi-tingginya salah satunya pelayanan keperawatan (Depkes RI, 2018).

Pelayanan keperawatan adalah proses asuhan keperawatan yang diberikan rumah sakit sebagai salah satu integrasi pelayanan kesehatan terdiri dari proses pengkajian, penetapan diagnosa keperawatan, intervensi, implementasi, dan evaluasi (Lemon, 2015).

Berdasarkan standar yang ditetapkan, salah satu usaha yang dilakukan untuk mempertahankan dan meningkatkan kualitas pelayanan yang termasuk asuhan keperawatan adalah rumah sakit wajib mengupayakan pemenuhan sasaran keselamatan pasien. Sasaran Keselamatan Pasien (SKP). Faktor yang mempengaruhi SKP dalam menjaga dan melindungi pasien dari KNC (kejadian nyaris cidera) dan KTD (kejadian tidak diharapkan) salah satunya saat dilakukannya timbang terima. Data yang didapatkan peneliti di RSUD Jaraga Sasameh Tahun 2018 melaporkan kerjadian KNC sebanyak 14 kasus dan KTD 10 kasus. Hal ini merupakan dampak dari tidak efektifnya timbang terima.

Timbang terima merupakan teknik yang digunakan untuk menyampaikan dan menerima laporan sehubungan dengan keadaan klien dilakukan antar perawat dengan perawat maupun antara perawat dengan klien secara akurat serta lebih nyata, dilakukan harus bersifat jelas, singkat dan lengkap (Nursalam, 2015). Apabila komunikasi dalam timbang terima tidak efektif dapat menyebabkan kesalahan dalam kesinambungan pelayanan dan pengobatan yang tidak tepat serta mengakibatkan potensi kerugian bagi pasien. Institute $O f$ Medicine (IOM) melaporkan kegagalan awal dalam keselamatan pasien sering terjadi akibat serah terima pasien yang tidak memadai (Kesrianti, dkk, 2014).

Hasil studi pendahuluan yang dilaksanakan peneliti melalui wawancara kepada 10 perawat rawat inap di Rumah Sakit Jaraga Sasameh Buntok tepatnya di Ruang Jati melaporkan bahwa, penerapan timbang terima belum berjalan dengan optimal sesuai dengan SOP. Contohnya, hanya 2 perawat yang melaksanaan timbang terima sesuai SOP. Sedangkan 8 perawat 
lainnya hanya melakukan timbang terima di nurse station, tidak menyebutkan diagnosa keperawatan, dan tidak menerangkan intervensi keperawatan yang sedang dan akan dilakukan terhadap pasien. Alasan 8 perawat tidak melakukan timbang terima sesuai dengan SOP yaitu tidak hafal dan paham poin-poin yang akan disampaikan, tidak pernah membuka dan dilakukan review bersama terkait SOP timbang terima. Selain itu juga dari data KNC sebanyak 11 kasus dan KTD sebanyak 8 kasus pada tahun 2018.

Hal ini dapat mengakibatkan kerugian pada pasien. Berdasarkan hasil penelitian Farida Marjani, dkk (2016) didapatkan data terjadi insiden keselamatan pasien sebanyak 8 pasien dan 22 pasien tidak terjadi kejadian insiden keselamatan pasien dikarenakan ketidakefektifan timbang terima.

Berdasarkan dampak yang dapat ditimbulkan karena pelaksanaan timbang terima yang tidak baik dan optimal dan hasil studi pendahuluan di RSUD Jaraga Sasameh, maka menurut peneliti perlu dilakukan penelitian dengan judul, “Gambaran Pelaksanaan Timbang Terima oleh perawat di ruang rawat inap RSUD Jaraga Sasameh”.

\section{METODE}

Penelitian ini merupakan jenis penelitian kuantitatif dengan menggunakan rancangan penelitian deskriptif dan teknik survei dalam pengumpulan data. Sampel yang dilibatkan dalam penelitian ini sebanyak 50 perawat yang bertugas di ruang rawat inap Jati, karuing, cendana atas, cendana bawah, cemaran, ramin, pinus, perinathologi, ICU RSUD Jagara Sasameh. Pengumpulan data yang digunakan peneliti untuk mendapatkan data tentang timbang terima adalah lembar observasi yang di adopsi dari SPO RSUD Jaraga Sasameh mengenai pelaksanaan timbang terima oleh perawat. Skala yang digunakan adalah skala Guttman dengan pertanyaan tertutup. Penggunaan skala Guttman karena pendekatan penelitian adalah pendekatan obsevasional. Lembar observasi terdiri dari 2 aspek pilihan yaitu “dilaksanakan" dan "tidak dilaksanakan".

Peneliti dibantu oleh dua asisten peneliti dan telah dilakukan uji Cohen Kappa, dengan alasan agar asisten peneliti mempunyai persepsi yang sama dengan peneliti mengenai isi setiap langkah SOP timbang terima. Nilai 1 artinya persepsi sama atau sangat kuat persamaan persepsi peneliti dengan asisten peneliti. Analisa data yang digunakan adalah univariat deskriptif, bila skor kuesioner 7,6-11 artinya baik, skor 
3,8- 7,5 artinya cukup, sedangkan 0-3,7 artinya kurang.

Terkait etika penelitian memegang teguh sikap ilmiah (scientificattitude) dan menggunakan prinsip-prinsip etika penelitian seperti menghormati harkat martabat manusia, menjaga kerahasiaan, keadilan, manfaat penelitian dan tidak berbahaya. Penelitian ini telah lulus etik dengan nomor : 027/LPPM/STIKESSI/IV/2020.

\section{HASIL}

\section{Karakteristik Responden}

Karakteristik responden dalam penelitian ini terdiri dari kategori usia, jenis kelamin, pendidikan, dan lama bekerja. berikut paparan karakteristik responden:

Tabel 1. Kategori Usia Responden

\begin{tabular}{clcc}
\hline No & \multicolumn{1}{c}{ Usia } & f & \% \\
\hline 1 & $\begin{array}{l}\text { 17-25 Tahun } \\
\text { (Remaja Akhir) } \\
2\end{array}$ & 11 & 22 \\
& $\begin{array}{l}\text { 26-35 Tahun } \\
\text { (Dewasa Awal) } \\
3\end{array}$ & 20 & 40 \\
& $\begin{array}{l}\text { (D6-45 Tahun } \\
\text { (Dewasa Akhir) }\end{array}$ & 14 & 28 \\
4 & $\begin{array}{l}\text { 46-55 Tahun } \\
\text { (Lansia Awal) }\end{array}$ & 5 & 10 \\
\hline & Total & 50 & 100 \\
\hline
\end{tabular}

Tabel 1 diatas menunjukkan sebagian besar perawat dalam penelitian berkategori usia dewasa awal (26-35 tahun) sebanyak $40 \%$ atau 20 perawat. Sedangkan kategori usia jumlahnya sedikit yaitu kategori lansia awal (46-55 tahun) sebanyak 10\% atau 5 perawat.

Tabel 2. Kategori Jenis Kelamin

\begin{tabular}{lcc}
\hline \multicolumn{1}{c}{ Jenis Kelamin } & f & \% \\
\hline Laki-Laki & 13 & 26 \\
Perempuan & 37 & 74 \\
\hline \multicolumn{1}{c}{ Total } & 50 & 100 \\
\hline
\end{tabular}

Tabel 2 menunjukkan bahwa sebagian besar responden dalam penelitian ini berjenis kelamin perempuan yakni sebanyak 37 perawat atau $74 \%$. Sedangkan yang berjenis kelamin laki-laki sebanyak 13 perawat atau $26 \%$.

Tabel 3. Tingkat Pendidikan Responen

\begin{tabular}{clcc}
\hline No & Pendidikan & f & $\%$ \\
\hline 1 & DIII Keperawatan & 35 & 70 \\
2 & Profesi Ners & 15 & 30 \\
\hline & Total & 50 & 100 \\
\hline
\end{tabular}


Tabel 3. Menunjukkan bahwa sebagian besar responden berpendidikan DIII keperawatan yaitu sebanyak 35 perawat atau $70 \%$, sedangkan sisanya adalah yang berpendidikan S1/profesi Ners sebanyak 15 perawat atau $30 \%$.

Tabel 4. Lama Bekerja Responen

\begin{tabular}{clcc}
\hline No & Lama Bekerja & f & \% \\
\hline 1 & $<5$ tahun & 10 & 20 \\
2 & $5-10$ tahun & 15 & 30 \\
3 & $>10$ tahun & 25 & 50 \\
\hline & Total & 50 & 100 \\
\hline
\end{tabular}

Tabel 4.4. Memamparkan bahwa responden yang bekerja <5 tahun sebanyak 10 perawat atau $20 \%$, bekerja 5-10 tahun sebanyak 15 30\%, dan >10 tahun sebanyak 25 50\%. Dapat disimpulkan, bahwa sebagian besar responden bekerja > 10 tahun di RSUD Jaraga Sasameh.

2. Hasil Observasi Timbang terima Perawat RSUD Jaraga Sasameh

Tabel 5. Hasil observasi 1, 2, dan 3

\begin{tabular}{cccc}
\hline Kategori & Observasi & Observasi & Observasi \\
& 1 & 2 & 3 \\
\hline
\end{tabular}

\begin{tabular}{lcccccc}
\hline & $f$ & $\%$ & $f$ & $\%$ & $f$ & $\%$ \\
\hline Kurang & 0 & 0 & 0 & 0 & 2 & 4 \\
Cukup & 44 & 88 & 44 & 88 & 43 & 86 \\
Baik & 6 & 12 & 6 & 12 & 5 & 10 \\
\hline Total & 50 & 100 & 50 & 100 & 50 & 100 \\
\hline
\end{tabular}

Tabel 5 diatas menunjukkan bahwa sebagian besar perawat melakukan timbang terima dengan cukup. Hasil penelitian pada observasi 1 dan 2 sebanyak 44 perawat $(88 \%)$, dan observasi 2 sebanyak 43(86\%) perawat.

Data di atas menunjukkan masih banyak perawat yang melakukan timbang terima dengan cukup baik. Hal ini dapat dilihat pada tabel 5 yang menyimpulkan sebanyak > $80 \%$ perawat melakukan timbang terima sesuai dengan SOP RSUD Jaraga Sasameh.

\section{PEMBAHASAN}

Analisa peneliti menyatakan bahwa masih banyak perawat yang melakukan timbang terimadengan cukup baik. Hal ini dapat dilihat pada tabel 5 yang menyimpulkan sebanyak > 80\% perawat melakukan timbang terima 
sesuai dengan SOP RSUD Jaraga Sasameh.

Faktor yang memperngaruhi baik dan opimalnya kinerja perawat adalah usia, dimana Sutrisno menyatakan bahwa umur dibawah 30 tahun merupakan umur yang produktif dimana pada umur tersebut seseorang dapat mencapai hasil kerja secara optimal. Adapula lama kerja, dimana Pamungkas et,al., (2017) melaporkan bahwa faktor yang mempengaruhi produktivitas seseorang dalam bekerja adalah lama bekerja.

Bertambahnya usia akan mempengaruhi produktivitas seseorang dalam bekerja. Usia yang masih dalam masa produktif biasanya mempunyai tingkat produktivitas lebih tinggi dibandingkan dengan tenaga kerja yang sudah berusia tua sehingga fisik yang dimiliki menjadi lemah dan terbatas.

Pangemanan (2014) mengatakan umur tua dapat mempengaruhi produktivitas kerja. Hal ini dikarenakan umur tua merupakan proses menghilangnya secara perlahan-lahan kemampuan jaringan untuk memperbaiki diri, mengganti dan mempertahankan struktur dan fungsi normalnya Selain itu kebutuhan akan metabolisme tubuh semakin menurun pada saat orang berumur tua sehingga menyebabkan kemampuan kerja pun semakin kecil untuk melakukan pekerjaan yang bersifat monoton.

Jenis kelamin tidak dapat mempengaruhi kinerja dari perawat pelaksana karena baik perempuan maupun laki-laki memiliki kesempatan yang sama untuk berkarya. Hal ini sejalan dengan Model teori perilaku kinerja (Gibson, Ivancevish \& Donally, 1987 dalam Kurniadi.A, 2013) mengatakan bahwa jenis kelamin tidak temasuk dalam faktor-faktor yang mempengaruhi kinerja.

Semakin tingginya pendidikan maka akan semakin tinggi informasi dan semakin baik proses timbang terima yang dilakukan perawat. Perawat yang memiliki pendidikan yang lebih tinggi, pasti mendapatkan paparan pengetahuan terbaru dari proses belajar baik itu secara formal maupun non-formal. Sehingga, hal ini dapat mempengaruhi ketrampilan seorang perawat dalam melakukan asuhan keperawatan dalam hal ini melakukan proses timbang terima yang termasuk dalam proses keperawatan tahap evaluasi. 
Teori Ani (2012) mengatakan bahwa tingkat pengetahuan merupakan faktor predisposisi dalam berprilaku positif, karena dengan pengetahuan seseorang akan mulai mengenal atau mencoba melakukan suatu tindakan. Peneliti sebelumnya HG Kambuaya (2016) melaporkan bahwa terdapat hubungan yang signifikan antara pendidikan perawat dan lamanya kerja dengan kinerjaperawat di Rumah Sakit Umum Daerah Kabupaten Sorong. Hal ini dbuktikan dengan nilai $p=0.01$ $(<0,05)$.

Lama bekerja atau pengalaman bekerja dapat mempengaruhi ketrampilan perawat dalam melakukan timbang terima. Pamungkas et,al., (2017) melaporkan bahwa faktor yang mempengaruhi produktivitas seseorang dalam bekerja adalah lama bekerja.

\section{KESIMPULAN}

Adapun kesimpulan penelitian ini adalah sebagian besar perawat RSUD Jaraga Sasameh telah melakukan proses timbang terima dengan cukup baik. Hal ini dibuktikan dengan hasil observasi I dan II yaitu berkategori cukup sebanyak 44 responden (88\%) dan baik 6 responden (12\%) dan Observasi III yang berkategori kurang 2 (4\%), cukup 43 (86\%), dan baik 5 (10\%).

Saran bagi perawat agar meningkatkan pengetahuan dan jenjang pendidikan yang lebih tinggi, agar lebih memahami dan dapat mengaplikasikan ilmu yang didapat khususnya aplikasi proses timbang terima asuhan keperawatan di ruang rawat inap. Untuk pihak rumah sakit agar memberikan dukungan yang seluas-luasnya kepada SDM khususnya perawat dalam mengembangkan kemampuan profesional dalam memberikan asuhan keperawatan khususnya proses timbang terima

\section{UCAPAN TERIMA KASIH}

Ucapan terimakasih kami ucapkan kepada Institusi STIKES Suaka Insan Banjarmasin, pihak RSUD Jarage Sasameh Buntok, para penulis, mahasiswa yang telah membantu pembuatan karya tulis ini. Tidak lupa kami mengucapkan terimakasih kepada para responden yang telah berpartisipasi dan sangat kooperatif dalam proses penelitian. 


\section{REFERENSI}

HG Kambuaya. (2016). Hubungan Tingkat Pendidikan Dan Lamanya Kerja Dengan Kinerja Perawat Di Rumah Sakit Umum Kabupaten Sorong.ejournal Keperawatan (e-Kp) Volume 4 Nomor 1 Mei 2016

Kesrianti, A. M. (2014). Faktor-Faktor Yang Mempengaruhi Komunikasi Pada Saat Handover Di Ruang Rawat Inap Rumah Sakit Universitas Hasanuddin. Jurnalunhas

Nainggolan, R., Purwoko, A., \& Yuliarso, M. Z. (2012). Faktor-Faktor Yang Mempengaruhi Produktivitas Tenaga Kerja Pemanen Sawit Pada PT. Bio Nusantara Teknologi, Bengkulu. Jurnal Agrisep, 11(1), 3542.

Nursalam.

(2015).

Manajemen

Keperawatan: Aplikasi dalam Praktik Keperawatan Profesional Edisi 5. Jakarta: Salemba

Pamungkas, A. D. P., Hamid, D., \& Prasetya, A. (2017). Pengaruh Pendidikan dan Pengalaman Kerja Terhadap Kemampuan Kerja dan Kinerja Karyawan (Studi pada Karyawan PT. INKA (Persero). Jurnal Administrasi Bisnis, 43(1), 96-103.

Pangemanan, E. 2014. Hubungan Manajemen Waktu dengan Produktivitas Kerja Perawat Pelaksana di Irina A RSUP Prof. Dr. $R$. D. Kandou Manado. http://ejournal.unsrat.ac.id.pdf. diakses 28 Juli 2019.

Wirawan, K. E., Bagia, I. W., Si, M., \& Susila, G. P. A. J. (2014). Pengaruh Tingkat Pendidikan dan Pengalaman Kerja Terhadap
Kinerja Karyawan. Jurnal Jurusan Manajemen, 4(1), 1-10. 